\title{
ENTRE A “AUTOELIMINAÇÃO” E O ENFRENTAMENTO INCERTO: disposições e dissonâncias frente ao ensino superior público
}

\section{BETWEEN 'SELF ELIMINATION' AND AN UNCERTAIN CONCURRENCE: dispositions and dissonances towards public higher education}

\author{
Eduardo Vilar Bonaldi*
}

\begin{abstract}
Resumo
A partir da tendência à "autoeliminação" escolar entre jovens de meios populares, tendência classicamente identificada pela literatura pertinente, conforme exposto na discussão teórica que inicia o artigo, o texto busca evidenciar trajetos e agenciamentos de socialização familiar que operam contra a referida tendência entre jovens observados e entrevistados em uma iniciativa de cursinho popular localizada na zona norte da cidade de São Paulo. Como tais jovens tendem a valorizar e aspirar ao ingresso no ensino superior público, a partir de suas passagens pela iniciativa abordada, o texto também busca argumentar como certos aspectos e condições que modulam esses trajetos e agenciamentos tendem a se desdobrar em dissonâncias e desajustes experienciados por esses jovens em suas tentativas de enfrentamento da concorrência pelo ingresso em instituições universitárias públicas. Logo, na conclusão, o texto argumenta que os trajetos e agenciamentos de socialização familiar, reconstituídos ao longo do estudo, performam um movimento caracteristicamente dialético, ao longo do qual os informantes superam a tendência à "autoeliminação escolar", experienciando, contudo, dissonâncias e desajustes em suas tentativas de acessar o ensino superior público no país.
\end{abstract}

Palavras-chave: Capital cultural. Cursinhos populares. Jovens de camadas populares. Acesso ao ensino superior.

\begin{abstract}
As it is classically identified in the literature, the educational trajectories of underprivileged youth are frequently curtailed by the recurrent tendency toward 'self-elimination' among such youth. That being so, the text seeks to evidence how family socialization trajectories counterbalance the aforementioned tendency among the informants of a qualitative study undertaken in free-tuition "prep" course, located in the northern part of the city of São Paulo. As such informants tend to value and aspire the public higher education institutions, within their passages through such educational initiative, the text also seeks to evidence how certain aspects and conditions that shape their family socialization trajectories tend to unfold dissonances and mismatches regarding the informants' attempts to face the concurrence to gain access to some of the Brazilian public universities.

Thus, in the conclusion, the text argues that such family socialization trajectories, as they are reconstituted throughout the study, perform a characteristically dialectical movement during which the informants overcome the tendency towards educational 'self-elimination', experiencing, however, several dissonances and mismatches in their attempts to gain access to the national public higher education system.
\end{abstract}

Keywords: Cultural capital. Free-tuition "prep" courses. Underprivileged youth. Democratization of Higher Education.

\footnotetext{
${ }^{*}$ Doutor em Sociologia pela Universidade de São Paulo (2016). Professor Adjunto no Departamento de Sociologia e Ciência Política da Universidade Federal de Santa Catarina (UFSC). E-mail: eduvilarbon@gmail.com.
} 


\section{A “autoeliminação escolar”: da aceitação implícita ao enfrentamento incerto}

No âmbito internacional dos estudos sociológicos sobre educação, multiplicaram-se, a partir dos anos de 1960, os trabalhos e os referenciais teóricos que buscavam, cada qual ao seu modo, pensar o fenômeno educacional para além das lentes da coesão ou do suposto equilíbrio autorregulado do corpo social moderno (DURKHEIM, 1975; PARSONS, 1964). Inversamente, essa nova tendência buscou avançar a perspectiva crítica acerca da reprodução material e cultural qualitativamente distinta dos diferentes grupos socioculturais, cujos membros delineiam trajetórias tendencialmente diferentes entre si em suas passagens pelo sistema de ensino.

Nesse quadro, Baudelot e Establet (1975) apontam para a estruturação histórica de uma dupla e incomunicável rede de escolarização na França que tenderia a espelhar e a reproduzir as diferenças entre o trabalho intelectual e o trabalho manual, ou seja, entre a classe burguesa e a classe trabalhadora. Bowles e Gintis (1976) tratam das diferenças entre instituições escolares destinadas à classe média branca e aos guetos pobres negros nos EUA igualmente como constituidoras e reprodutoras de desigualdades semelhantes no sistema educacional norte-americano. Boudon (1974) e seu individualismo metodológico compreendem, por sua vez, tais desigualdades como emanadas do comportamento estratégico e racional de indivíduos localizados ante diferentes estruturas objetivas de incentivos e de restrições que resultam de suas diferentes posições de classe.

Já Bourdieu e Passeron $(1964,1970)$ tentaram explicar as desigualdades escolares a partir da homologia implícita entre as origens e trajetórias sociais que caracterizam, de um lado, os indivíduos que ocupam posições relevantes na seleção e na consagração de conteúdos e de competências oficialmente transmitidas pelas instituições escolares e, por outro, os estudantes caracterizados pela incorporação de altos volumes de capital cultural ao longo de seus trajetos sociais e escolares.

A despeito de seus diferentes partidos teóricos, todos esses estudos apontam para a tendência aos percursos escolares mais curtos, entre jovens de camadas pobres e trabalhadoras, caracterizados pela "autoeliminação escolar", ou seja, pela incorporação subjetiva, entre esses jovens, do sentimento de impossibilidade, de estranhamento ou de desfiliação ante a trajetórias escolares prolongadas ${ }^{1}$.

Contudo, o aprofundamento dos processos de massificação dos sistemas de ensino nos EUA e na Europa após a década de 1970 caracterizam-se pela substancial elevação da capacidade de inclusão do ensino suSperior em tais contextos nacionais (BEAUD, 2002) uma reação, inclusive, às críticas sobre a reprodução das desigualdades escolares realizadas pelos estudos acima referidos. Tal ampliação tendeu a engendrar o progressivo aumento de contingentes de

1 Devemos destacar aqui, igualmente, o trabalho de Paul Willis (1991) como um dos estudos etnográficos mais vívidos da literatura internacional sobre a tendência à "autoeliminação escolar". Willis evidencia, no referido estudo, como a "autoeliminação escolar" era deflagrada pelos sentidos de lealdade e de orgulho de classe entre jovens de meios trabalhadores na Inglaterra da década de 1970. 
estudantes de camadas socialmente desprivilegiadas que passam a alcançar os níveis mais altos dos sistemas educacionais.

A literatura internacional empreende, então, um giro a partir do qual o fenômeno da "autoeliminação escolar" passa a ser conectado, por outro lado, à investigação dos casos que se acumulam de estudantes de camadas desprivilegiadas que passam a alcançar o ensino suSperior, carregando, durante suas trajetórias escolares alongadas, as marcas e experiências do descompasso entre suas origens sociais e os níveis mais altos do sistema de ensino.

Além da tendência à ampla requalificação do valor simbólico dos diplomas dada a "inflação" de credenciais escolares - incitada por tal aprofundamento da massificação dos sistemas de ensino (BOURDIEU, 1998) - autores como Bourdieu também observarão que esses filhos dos estágios mais avançados da massificação tendem a se personificar como os "excluídos do interior" em suas instituições de ensino, ou seja, como subjetividades que se encaram como socialmente deslocadas ou culturalmente ilegítimas em tais instituições (BOURDIEU, 1998).

No Brasil, a ampliação do ensino suSperior a camadas sociais historicamente alheias a ele, teve início nos anos de 1990 através da massificação do nível de ensino que lhe é imediatamente anterior, conjugada à expansão do setor privado do enEsino suSperior ${ }^{2}$. Esses processos ensejaram a figura do "estudante-trabalhador" (ROMANELLI, 2003), isto é, de indivíduos acima da idade modular comumente associada à condição universitária (o período dos 18 aos 24 anos), que já acumulam um percurso considerável no mercado de trabalho, trabalhando em período integral e, logo, inclinados à preferência por graduações mais curtas e oferecidas em período noturno.

Na década seguinte, a relativa expansão do ensino suSperior nacional prosseguiu com a criação do PROUNI, em 2004 - um programa de concessão de bolsas a estudantes desprivilegiados no setor privado - bem como a partir da criação de novas universidades e institutos federais, tendo sido o acesso ao ensino superior público nacionalmente unificado (por meio do Sistema de Seleção Única, o SISU, conjugado ao Exame Nacional do Ensino Médio, o ENEM). Ademais, o acesso ao setor público torna-se, a partir de 2012, mediado pela progressiva implantação de um sistema de cotas sociais e raciais nessas universidades e institutos federais.

Desse modo, no contexto brasileiro, a ampliação - ainda que relativa e tardia - do sistema de ensino suSperior instiga a produção sociológica nacional, na área da educação, a ultrapassar as tradicionais indagações sobre a tendência à "autoeliminação" escolar no seio das classes desprivilegiadas para abordar determinados perfis sociais e raciais de jovens dessas camadas que passam a internalizar o ensino superior como um destino social e escolar possível, embora jamais assegurado, nem garantido, nem, tampouco, naturalizado", como ocorre às famílias de camadas médias e altas (GRÜN, 1992; NOGUEIRA, 2002).

2 Entre 1994 e 2008, as matrículas de ensino médio no país foram elevadas em cerca de 70\% (ALMEIDA, 2009), ao passo que, em 2011, 88\% das instituições de eesino sSperior no país pertenciam ao setor privado. Essas instituições concentravam então $72 \%$ das matrículas em cursos de graduação presenciais no país (BRASILI 2013). 
Desse modo, além dos estudos qualitativos de casos sobre as implicações das relações entre a família e a escola nas trajetórias escolares excepcionais de jovens de meios populares (ROMANELLI; NOGUEIRA; ZAGO, 2003), Wilson A. Mesquita (2012) e Márcia Lima (2013) investiram-se no estudo dos beneficiários do PROUNI na cidade de São Paulo. Ana Almeida e Maurício Enrica (2015) abordam a inclusão e a segmentação no ensino suSperior público de São Paulo, enquanto Graziela Perosa e Taline Costa (2015) focam o caso específico da Universidade Federal de São Paulo, Unifesp.

Em meu estudo de doutorado, conduzido entre os anos de 2012 e 2014, busquei contribuir com tal corrente de pesquisas ao abordar uma ocorrência empírica de outro fenômeno educacional, imbricado à relativa popularização do acesso ao ensino suSperior, que se multiplica desde os anos de 1990, ou seja, os "cursinhos populares".

Os chamados "cursinhos populares" são organizados a partir do engajamento voluntário ou militante de seus colaboradores, apresentando-se como gratuitos ou financiados a taxas módicas, sendo frequentemente (embora não necessariamente) focados na atração de perfis socioeconômicos e raciais de alunos historicamente excluídos do ensino suSperior público ( ZAGO, 2008).

O cursinho popular em que conduzi meu estudo é sediado em uma escola municipal na zona norte da cidade de São Paulo, sendo organizado e conduzido, desde o ano de 2011, por graduandos de universidades públicas da região metropolitana da cidade (sobretudo, da Universidade Federal do ABC, a UFABC, e da Unifesp).

Além da coleta de dados socioeconômicos sobre a origem e trajetória dos estudantes dessa iniciativa, a pesquisa de campo também abrangeu entrevistas em profundidade com 26 alunos do cursinho popular abordados para a reconstrução de suas trajetórias de socialização e de escolarização, assim como entrevistas conduzidas junto aos pais de seis desses entrevistados. Todos esses procedimentos de pesquisa foram organizados por uma experiência etnográfica de "observação participante", segundo a qual eu me inseri, no universo estudado, como professor da iniciativa abordada entre os anos de 2012 e 2014, buscando me apropriar reflexivamente de tal experiência como outra fonte de produção de dados qualitativos sobre esse universo de pesquisa.

Pelo cursinho investigado, passam cerca de 400 estudantes por ano. Com idades entre 17 e 19 anos, em geral, esses jovens cursaram o Ensino Médio em escolas públicas da zona norte de São Paulo no ano anterior ao seu ingresso na iniciativa, ou, por vezes, cursam a iniciativa simultaneamente ao terceiro ano do ensino médio (EM, doravante): caso de Eraldo (18 anos), um dos seis filhos de Anelize, 38 anos, auxiliar de limpeza.

Anelize perdeu o pai, funcionário público, cujo cargo ela não soube especificar, aos seis anos de idade, fato que teria levado ela e seus três irmãos ao abandono da escola, segundo reporta na entrevista. Desse modo, ela interrompeu seus estudos aos 13 anos de idade, quando ainda cursava o quinto ano do ensino primário. Seu ingresso no mercado de trabalho deu-se 
ainda antes do abandono da escola, aos 10 anos de idade, a partir de oportunidades de trabalho mediadas por suas próprias professoras, cientes das dificuldades financeiras de sua família.

Desse modo, desde os 10 anos de idade, a mãe de Eraldo constituiu uma trajetória empregatícia precária e informal em ocupações com forte modulação de gênero (empregada doméstica e costureira, por exemplo) ao longo da qual, como a entrevistada afirma, acumulou "muita experiência e pouca carteira assinada". Sua mobilidade entre diferentes lugares de moradia na periferia da área metropolitana de São Paulo acompanhou essa multiplicidade de vínculos empregatícios pouco duradouros, mediada por laços familiares que asseguram tanto indicações de emprego quanto possibilidades de coabitação nos terrenos e casas de membros de sua família estendida, que se alternaram a períodos de aluguel de sua própria moradia.

Durante esse percurso, desde a morte do pai, Anelize intercalou períodos de moradia nas cidades de Itapevi, Francisco Morato e em bairros da zona norte de São Paulo, retornando, nos anos precedentes à entrevista (realizada em 2014), ao bairro do Jd. Pery Alto, no extremo da zona norte da cidade, onde mora com duas tias no terreno anexo à casa de sua avó.

A fixação no bairro encadeou-se à experiência de emprego formal como auxiliar de limpeza em uma empresa multinacional de engenharia, fato combinado, ainda, ao retorno de Anelize aos bancos escolares, cursando o segundo ano do EM em um curso supletivo próximo à sua casa no momento da entrevista.

Certamente, há famílias de estudantes do Allende que registram trajetórias empregatícias mais estáveis e formalizadas do que o percurso de Anelize (principalmente, no caso recorrente de pais funcionários públicos de baixo escalão), com maior sedentarização, inclusive, em seus locais de moradia. Não obstante, uma condição parece comum aos grupos familiares retratados no estudo: os pais dos estudantes do Allende enxergam-se como "bloqueados" em suas trajetórias ocupacionais, atribuindo tal bloqueio - fato central, para meu problema de pesquisa - à limitação de suas credenciais escolares. Tal percepção de "bloqueio" é constantemente reportado tanto pelos pais dos entrevistados, quanto pelos estudantes.

Conforme a coleta de dados sobre a realidade socioeconômica das famílias dos alunos indicou, 56\% de seus pais não haviam completado o EM. Assim como Anelize, muitos entre eles haviam buscado retomar recentemente seus processos de escolarização, interrompidos durante suas adolescências.

Porém, dada as dificuldades implicadas nessas tentativas de retomar seus próprios investimentos educacionais, de um lado, e premidos pelo sentimento subjetivo de "bloqueio" em seus percursos ocupacionais, por outro, os pais desses jovens buscam projetar para os filhos a superação das razões que atribuem a sua própria sensação de bloqueio, ou seja, eles buscam projetar aos filhos a superação das limitadas credenciais educacionais que, conforme esses pais interpretam, teriam "travado" suas próprias trajetórias no mundo do trabalho.

Nesse quadro, portanto, o presente texto busca evidenciar, primeiramente, como os trajetos de socialização familiar dos informantes da iniciativa abordada os imunizam contra 
a "autoeliminação" escolar, inculcando nestes jovens expectativas de escolarização alongadas, ao mesmo tempo em que, no sentido reverso, entretanto, o texto também buscará argumentar, posteriormente, como tais percursos de socialização revelam-se como dissonantes ante as exigências (implícitas e explícitas) dos exames vestibulares das universidades públicas: destinos educacionais valorados e pretendidos, como veremos, a partir da passagem dos informantes pelo cursinho popular abordado no estudo.

\section{A incorporação das disposições contra a "autoeliminação escolar"}

Para evidenciar a incorporação das disposições que incitam os jovens retratados à superação da "autoeliminação escolar" - tendência amplamente identificada entre jovens de meio popular na literatura - acompanharemos, em primeiro lugar, os seguintes aspectos e dimensões próprias às trajetórias sociais e educacionais dos informantes do estudo: A) os investimentos parentais na distinção moral e disciplinar dos informantes frente a seus pares de idade nos bairros em que habitam (condição que ampara as propensões ao investimento escolar, entre os jovens observados no estudo) B) a vigilância familiar sobre o despertar da sexualidade e da vida afetiva dos informantes como estratégia parental para evitar casos de gravidez "precoce" que possam obstaculizar as trajetórias educacionais de seus filhos ou filhas e $\mathrm{C}$ ) a influência exercida pelos agentes que a literatura qualifica como "modelos impulsionadores" das trajetórias educacionais dos informantes do estudo, presentes e ativos em suas redes de relações imediatas (família, amigos, vizinhança etc.)

\section{A) A distinção moral e disciplinar}

Em seu estudo sobre os casos de sucesso escolar socialmente improváveis entre crianças de meios populares no ensino primário, Bernard Lahire (1997) argumenta que uma ordem moral e disciplinar rigorosa e distintiva, estabelecida no contexto de socialização familiar de seus entrevistados positivamente avaliados pela instituição escolar, inscreve-se como uma das dimensões de socialização de crianças e jovens no meio popular que lhes predispõe ao investimento bem-sucedido no jogo escolar.

Lahire (1997) argumenta, portanto, como os pais buscam introjetar em seus filhos um sentimento subjetivo de distinção frente às demais crianças do bairro, ancorando justamente nessa ordem moral e disciplinar rigorosa a narrativa sobre a honra e a reputação do grupo familiar nas redes de relações imediatas em que essa família nuclear se insere junto aos membros de suas famílias estendidas ou aos seus vizinhos. Fato este que pode se desdobrar, inclusive (como veremos no caso da primeira informante mencionada), em estratégias parentais para a seleção de experiências de socialização e de escolarização de seus filhos e filhas, bem como de amizades entre seus pares de idade, fora dos bairros estigmatizados em que esses grupos familiares habitam. 
Como observaremos, esta é uma das condições que favorecem a incorporação de propensões contra a "autoeliminação escolar" dos informantes da amostra: destino modular entre seus pares de idade nos bairros pobres e estigmatizados em que residem, conforme vimos na discussão teórica.

Nesse sentido, Carla, 17 anos, moradora da Vila Brasilândia, bairro periférico da zona norte de São Paulo, representa um caso limite, no qual estratégias e agenciamentos acionados por seu pai (EM completo, metalúrgico) praticamente subtraem a menina do convívio com os jovens de seu bairro, caracterizados geralmente por trajetos escolares encerrados antes do possível acesso ao ensino superior.

Desse modo, por escolha do pai, a garota saiu da pequena escola particular onde realizou o Ensino Fundamental (EF) na Vila Brasilândia para realizar seus estudos secundários no próprio colégio público que sedia o cursinho investigado, localizado próximo à rodoviária do Tietê, na região do bairro de Santana, o centro gravitacional da sociabilidade de classe média na zona norte da cidade.

Após passar as manhãs no colégio longe de casa, Carla frequenta, às tardes, as aulas de teatro e o grupo de literatura do próprio colégio ou, ainda, as aulas de inglês gratuitas em uma iniciativa pública próxima ao colégio. Além disso, ela também visita constantemente sua avó que também mora na região de Santana.

Tais estratégias parentais inculcaram na garota uma visão extremamente crítica sobre a ausência objetiva de equipamentos culturais e escolares em seu bairro de moradia, frequentemente alocada, durante a entrevista, como explicação para suas representações depreciativas sobre as práticas e gostos culturais, bem como sobre as expectativas educacionais dos jovens que lá moram. Sobre a Vila Brasilândia, portanto, sua jovem moradora afirma:

\footnotetext{
Olha, no meu bairro, não tem nada! Lá não tem nada! Lá tem um problema de invasão, porque lá não existe nenhuma fiscalização, o pessoal chega lá e vai derrubando, porque é perto da Serra da Cantareira... O pessoal vai invadindo e vai criando aquela favela, aquele morro, poucas casas são legais ali, são legalizadas... E lá não tem nada... Tem uma fábrica de cultura ali no Cachoeirinha, perto do hipermercado Andorinha.... Aquilo pra mim é a única coisa que eu vejo... Escola particular que era a minha [no ensino fundamental], na Parada Pinto, eu estudei no Quatorze de Julho, tem outro centro cultural ali, não tem nada pra fazer lá... Minha vida acontece em Santana, de Santana pro centro, daqui pra lá...
}

Como vimos, Carla afirma que sua vida “ (...) acontece em Santana, de Santana pro centro", distinguindo-se implicitamente, portanto, dos espaços e dos agentes que marcam a sociabilidade em seu bairro periférico e estigmatizado, a Vila Brasilândia. Esses sentimentos de distinção são explicitados recorrentemente, ao longo de algumas entrevistas, a partir da comparação, estruturada discursivamente pelos próprios entrevistados, entre seus estilos de vida e os estilos de vida que marcam a experiência social e as expectativas educacionais encurtadas 
de seus pares de idade nos bairros em que habitam: ou seja, vizinhos ou, por vezes, primos em seus círculos familiares estendidos para além de suas famílias nucleares.

Os estilos de vida desses pares de idade são frequentemente sintetizados, na fala dos informantes, por uma forma determinada de preferência musical que organizaria padrões de consumo, de sociabilidade juvenil e, até mesmo de sexualidade, a baixos investimentos educacionais e poucas aspirações de mobilidade social. Essa preferência musical seria, como Gisele (17 anos, pai, porteiro com EF incompleto, mãe, empregada doméstica, com EM realizado através de supletivo) afirma, o "funk ostentação".

\footnotetext{
Meus pais e minha família cobram muito de mim pelo fato de ninguém na família ter ido atrás. Eles sentem muito pelos meus primos não terem terminado a faculdade e agora que meu tio terminou a faculdade, acho que eles [os primos] têm uma vontade... Mas é só uma vontade porque os [risos] "primos da ostentação" só pensam no hoje, no agora, não pensam no amanhã... Eles são da ostentação... Do funk... [risos]

[pesquisador]: Como eles ostentam?

Gastando o salário todo numa blusa, numa bermuda, num tênis colorido, na moto que é o brinquedinho deles lá e essas coisas assim, eles só pensam nisso...
}

Os "primos da ostentação" de Gisele gostam de funk e despendem suas rendas mensais em bens de consumo valorados no circuito de sociabilidade juvenil que frequentam (o "tênis colorido" e a moto como um "brinquedinho deles lá"). Segundo a entrevistada, eles "só pensam no hoje, no agora, não pensam no amanhã”, ou seja, eles centrariam (de acordo com a visão da garota) seu hedonismo consumista na fruição despreocupada do presente, apresentando pouca inclinação para investimentos de longo prazo - como o investimento educacional, por exemplo - que demandaria o autocontrole ascético de suas pulsões de consumo, de sociabilidade e de sexualidade, no presente, para a projetada efetivação de planos de ascensão e mobilidade no futuro.

Os entrevistados situam comumente os esforços e agenciamentos de seus pais (assim como Gisele começa a citação transcrita, abordando as "cobranças" de seus pais) como o motivo indutor de seus estilos de vida explicitamente marcados como distintos ante o estilo "funk ostentação", também delineado e apontado em outras entrevistas.

Assim, os entrevistados tematizam frequentemente seus hábitos de consumo frugais, a moderação de suas atividades de lazer e, sobretudo, seus investimentos educacionais (como a frequência ao cursinho popular, por exemplo) como expressões de um estilo de vida orientado por uma outra relação com o próprio tempo, isto é, de um estilo de vida marcado pelo autocontrole ascético no presente que visa a efetivação de planos de mobilidade no futuro, jamais justificados, entretanto, nas narrativas dos entrevistados, a partir da realização a posteriori de eventuais desejos consumistas, mas sim a partir da alegada missão de dotar seus filhos (ou seja, sua futura unidade familiar e doméstica) de melhores condições de vida, imprimindo seguimento, 
portanto, aos esforços que eles atribuem recorrentemente aos seus pais no sentido de provê-los com as condições mínimas necessárias para que eles estudem.

\section{B) O acompanhamento parental sobre a vida afetiva e sexual dos estudantes}

Classicamente, a sociologia da educação evidencia que o acompanhamento da escolaridade é uma prerrogativa tendencialmente associada - sobretudo nas camadas populares - ao amplo conjunto dos deveres e de responsabilidades a partir da quais a maternidade é culturalmente concebida (TERRAIL, 1992; LAHIRE, 1997). Minha pesquisa evidenciou que, no grupo abordado, esse dever materno de acompanhamento da escolaridade também conduz as mães, ao longo da adolescência de seus filhos e filhas, a determinados agenciamentos exercidos no sentido de tentar evitar a reprodução, na trajetória de sua prole, de um traço recorrente nos percursos biográficos dessas próprias mães ou de seus cônjuges, isto é, a ocorrência de casos de gravidez anteriores à conclusão da escolarização básica ${ }^{3}$. Este fato biográfico é comumente identificado, por tais mães, como uma das principais forças que determinaram o encurtamento de suas próprias trajetórias escolares, assim como as de seus cônjuges.

Ainda que minha amostra tenha contemplado entrevistas com jovens e grupos familiares que frequentavam ativamente confissões religiosas diferentes entre si (catolicismo, budismo e confissões neopentecostais), os relatos de acompanhamento da vida afetiva e sexual dos jovens não emergiam, nas entrevistas, como modulados por preocupações associadas à moralidade religiosa, mas sim justamente às referidas tentativas de evitar a reprodução das ocorrências de gravidez "precoce": sentido associado a tais episódios pelos próprios entrevistados, bem como por suas mães.

Bárbara (18 anos) decidiu contar a sua mãe quando perdeu a virgindade, pois a mãe (Superior incompleto, digitadora de planilhas) sempre havia agido, conforme a garota afirma durante a entrevista, como uma "amiga" com ela e, igualmente, com sua irmã mais nova. Aliás, quando essa irmã contara à mãe que havia beijado um garoto na escola pela primeira vez, aos 13 anos de idade, Bárbara recorda que a mãe não brigara com a menina e nem contara a ninguém aquele "segredo". Ao receber a notícia sobre a primeira experiência sexual da garota, sua mãe reagiu da seguinte forma:

Ela me contou que, com 19 anos, ficou grávida e minha vó pôs ela pra fora de casa. Ela disse: "tô falando isso pra você, tô contando isso pra você, pra não acontecer com você... Por isso que eu te falo, toma o remédio [anticoncepcional], se você quiser, eu te levo no médico... O que eu passei, eu sofri muito e eu não quero isso pra você”. Então ela conversa bastante sobre essas coisas comigo e com a minha irmã.

Mas tais agenciamentos não parecem ocorrer apenas entre as garotas. Quando pergunto a Eraldo se ele pensa em "casar e ter filhos", o garoto reproduz, de forma bem humorada, as

3 Ou seja, segundo a idade modal reconhecida para a conclusão do ensino médio, 17-18 anos. 
constantes pregações maternas para que ele jamais se esqueça de levar preservativos consigo ${ }^{4}$. Na transcrição abaixo, observamos como a mãe de Eraldo - Anelize (38 anos, EM incompleto, auxiliar de limpeza, já mencionada ao início do texto) - afirma diretamente que engravidar uma garota faria Eraldo "ver o ciclo da família girando de novo".

[pesquisador] E família? Você pensa em casar e ter filhos ou não?

Em casar e ter filho? Olha, eu confesso que eu venho pensando nesse assunto há um tempinho, mas não tenho uma opinião... A priori, não, eu tô num momento da minha vida em que o estudo é muito importante, tanto que minha mãe sempre fala "Eraldo, usa a camisinha!" [risos] Não é só o RG não, é a camisinha também! Ela preza muito isso também, ela fala "Eraldo, se você quer ferrar sua vida hoje, faça essa besteira [ter um filho], faça essa besteira que você vai ver o ciclo da família girando de novo". Ela fala "Não faça filho!" e ela conseguiu implementar isso na minha mente, né? Eu tomo cuidado também! [risos]

Desse modo, enfatizo que tais agenciamentos parecem incidir indistintamente sobre garotos e garotas da amostra, configurando sua modulação de gênero mais pertinente a partir do fato, já afirmado, de que tal acompanhamento tende a ser exercido unilateralmente pelas mães dos jovens e não por seus pais, tanto nas situações familiares de pais casados, quanto naquelas em que os progenitores são separados ou divorciados.

\section{C) Modelos impulsionadores de trajetórias educacionais}

A literatura nacional sobre universitários de camadas populares ressalta, como uma das principais dificuldades enfrentadas por esses agentes, a inicial ausência ou rarefação de "capital informacional" sobre o sistema de ensino superior experimentada por esses jovens (SILVA, 2003; ZAGO, 2006; VIANA, 1998). Em outros termos, esses estudantes relatam dispor, ao início de suas trajetórias, de pouco conhecimento e informações sobre os processos seletivos, as carreiras e as próprias instituições universitárias. Essa lacuna dificulta a incorporação da condição de universitário como um destino subjetivamente aspirado por esses jovens, bem como o mapeamento dos possíveis horizontes (em termos de carreiras, de instituições, bem como de estratégias para o enfrentamento dos processos seletivos) a partir dos quais esse destino poderia ser alcançado.

Por outrolado, essa literatura também evidencia a crescente relevância que pessoas diplomadas no ensino suSperior e inseridas nas redes de relações imediatas desses jovens - tais como parentes, amigos, vizinhos, colegas de trabalho etc. - podem assumir na conformação de suas trajetórias de acesso ao referido nível de ensino. Tendo alcançado previamente a condição de universitários através

4 O garoto também revela que sua mãe certifica-se constantemente se ele está portando o RG, quando sai de casa, pelo receio de que o menino sofra uma abordagem policial violenta. 
das novas possibilidades de acesso criadas ao longo do recente processo de (relativa) expansão do sistema universitário nacional, esses universitários aproximam, portanto, os jovens de camadas populares (inseridos em seus círculos de relações imediatas na família, vizinhança, trabalho etc.) de uma realidade que se afigura inicialmente como distante e alheia a ambos.

Nesse sentido, a literatura denomina esses universitários que desempenham papéis relevantes nas redes de relações imediatas dos jovens retratados no estudo como "modelos impulsionadores de trajetórias educacionais"5.

Entre meus entrevistados, a garota Marisa (17 anos) ressentiu-se do fato de que, no colégio público em que realizou o EM, pouco se falava sobre faculdades e vestibulares. Contudo, a garota tinha uma prima mais velha, cuja influência sobre a menina exemplifica paradigmaticamente os possíveis efeitos da interação junto a modelos impulsionadores de trajetórias educacionais.

Essa prima alguns anos mais velha do que Marisa havia conseguido uma bolsa integral do PROUNI para estudar Economia, conjugando seus estudos universitários a um trabalho em tempo integral. Ela explicou à garota o que era o PROUNI, todos os critérios necessários à inscrição no programa e, igualmente, emprestou-lhe as apostilas de um curso pré-vestibular privado, que havia sido concedida à estudante de Economia pelo namorado: apostila através da qual essa prima havia se preparado para prestar o ENEM.

Ademais, o contato com a prima motivou a mudança da carreira que a garota pretendia cursar, passando de seus planos iniciais de cursar Hotelaria ou Turismo para a ideia de prestar Administração, uma vez que a prima lhe havia convencido de que este curso abriria à garota mais oportunidades de emprego.

Desse modo, vemos como os modelos impulsionadores operam, consciente ou inconscientemente, como nós difusores de capital informacional - ao longo das redes de relações em que se inserem na família estendida, na vizinhança ou no trabalho - sobre as novas oportunidades de ingresso no ensino suSperior brasileiro, ao mesmo tempo em que encarnam o acesso a esse nível de ensino como um destino social possível aos demais jovens de seus círculos de relações imediatas: ativa-se aqui, portanto, uma espécie de efeito multiplicador das trajetórias de alcance do enEsino suSperior por jovens de camadas populares, transmitido pelas redes de relações que ligam esses jovens a diplomados do ensino superior de origens e trajetos sociais assemelhados aos deles.

\section{A perspectiva do ensino superior público: dissonâncias e desajustes...}

Ao adentrar o cursinho popular investigado, os informantes passam a travar contato regular com outros potenciais “impulsionadores" de trajetórias educacionais, isto é, os

\footnotetext{
5 Esta denominação inspirou-se fortemente no trabalho de Viana (1998, p.6) que integrou, como uma de suas questões de pesquisa, a investigação sobre os "grupos de referência", ou melhor, os elementos impulsionadores de trajetórias educacionais de universitários de origem popular.
} 
professores e organizadores da iniciativa de cursinho abordada no estudo, em geral, graduandos de universidades públicas nas carreiras de Humanidades, Pedagogia e Licenciaturas. A partir desse contato, o horizonte de destinos educacionais aspirado por esses jovens amplia-se, portanto, ao conhecimento, à valorização e à pretensão ao ingresso em universidades públicas.

Não obstante, esse alargamento termina por evidenciar, frequentemente, as dissonâncias e desajustes observáveis entre as disposições escolares e as práticas culturais desses jovens originados de meios populares e as exigências, implícitas e explícitas, dos exames vestibulares que regulam as chances de ingresso no ensino superior público brasileiro.

Nesse sentido, para além da incorporação das disposições que evitam a "autoeliminação escolar" entre esses jovens, a pesquisa tornou-se capaz de apreender, por outro lado, determinados aspectos dos trajetos de socialização familiar dos informantes que se traduzem em dificuldades e obstáculos experienciados em suas tentativas de acessar o ensino superior público: destino educacional valorizado e pretendido a partir da passagem pelo cursinho popular.

Neste momento do texto, passo a tratar, portanto, de alguns desses aspectos. Buscarei evidenciar, desse modo, como os trajetos de socialização familiar dos informantes se traduzem em práticas culturais e linguísticas dissonantes ante as competências e conhecimentos valorizados pelos exames vestibulares de instituições públicas, bem como em rarefeitas oportunidades de "familiarização" desses jovens com o mundo do ensino superior e de suas carreiras. Veremos que tal "familiarização" tende a ocorrer somente a partir da presença de "modelos impulsionadores" de trajetórias educacionais nas redes de relações desses jovens.

Como estratégia de pesquisa para apreender e delinear essas dissonâncias e desajustes, recorrerei à comparação entre o material qualitativo produzido no estudo sobre a iniciativa de cursinho popular abordada e o material de entrevistas em profundidade com estudantes de engenharia de uma universidade pública recentemente implantada na região metropolitana de São Paulo, produzido para a elaboração de outro estudo (BONALDI; SILVA, 2014). Para sistematizar este procedimento comparativo, especificarei as condições que possibilitam a interpretação confrontativa dessas duas amostras de estudo qualitativo.

Segundo a releitura da perspectiva bourdiesiana a partir da investida radicalmente etnográfica de Annette Lareau (2003) $)^{6}$, a reconstituição das disposições socialmente gestadas e transmitidas na experiência familiar, mas desigualmente valoradas pela instituição escolar, tornase evidente quando tais experiências de socialização primária - comparativamente distintas entre grupos socioeconômicos diferentes entre si - são compreendidas a partir de articulações entre três dimensões de observação fundamentais do referido estudo: A) a incorporação de disposições linguísticas qualitativamente diferenciais entre as classes sociais; B) a forma como se

$6 \mathrm{O}$ trabalho da autora investiga comparativamente o cotidiano de famílias pertencentes às classes média, trabalhadora e pobre dos EUA, buscando abordar diferentes processos de socialização familiar desigualmente dispostos no espaço social a partir de investidas etnográficas ao longo das quais a pesquisadora e seus assistentes acompanham as famílias em reuniões escolares, idas ao médico, refeições conjuntas ou em momentos nos quais a família convive nos tempos livres da escola e do trabalho. 
organiza o convívio entre pais e filhos, com especial atenção para práticas e gostos culturais, bem como para as experiências de fruição do tempo livre que tais formas de convívio possibilitam e, por fim, C) a estruturação ou não do cotidiano das crianças e jovens por meio de cursos ou de formações extraescolares.

Esta esquematização proposta por Lareau (2003) é útil para ordenar a exposição e a análise do material qualitativo de meu estudo no que concerne ao papel implicitamente desempenhado pelos grupos familiares dos informantes na transmissão e na inculcação de disposições objetivamente descompassadas ante as competências e conhecimentos valoradas pelos processos seletivos de acesso ao ensino superior público no país.

Seguindo tal estratégia de pesquisa, ancorada na abordagem comparativa entre processos de socialização familiar próprios a grupos desigualmente dispostos no espaço social, será útil, como adiantei acima, confrontar o material qualitativo produzido no estudo sobre o cursinho popular (exposto e interpretado ao longo do presente texto) ao material qualitativo produzido em outra oportunidade, na qual dez estudantes de engenharia de uma universidade pública recentemente implantada na região metropolitana de São Paulo, a UFABC, foram entrevistados (BONALDI; SILVA, 2014).

Esse contraste revela-se como uma estratégia de pesquisa qualitativa que torna inteligíveis as dissonâncias e desajustes entre os trajetos de socialização familiar dos jovens do cursinho em relação às exigências (implícitas e explícitas) dos exames vestibulares, a partir da comparação entre esses trajetos e as experiências familiares qualitativamente distintas de jovens socializados em grupos familiares caracterizados por origens sociais mais privilegiadas.

Pois, ao contrário do que vimos sobre os grupos familiares dos jovens do cursinho popular abordado, as famílias dos estudantes de engenharia entrevistados possuem origens e trajetos sociais tipicamente associados à realidade da "classe média" paulista: pais com ensino superior completo, profissionais liberais ou quadros de gerência ou direção em empresas públicas e privadas, filhos escolarizados em estabelecimentos privados com alta frequência a cursos e formações extraescolares (sobretudo em línguas estrangeiras) etc.

Não obstante, é necessário ressaltar que os grupos familiares dos estudantes de engenharia originam-se de um lugar geográfico e urbano relativamente marginal no interior da região metropolitana de São Paulo, ou seja, eles são a classe média originada dos processos de urbanização e de industrialização que marcam a conurbação dos três municípios ${ }^{7}$ que formam o ABC paulista, região na qual se situa a UFABC.

Dito de outro modo, portanto, esses entrevistados vivenciam condições de socialização e de escolarização assemelhadas, mas nunca exatamente idênticas, aos seus pares de origem social que residem e circulam pelos bairros social e culturalmente mais valorizados ou bem equipados (em termos de instituições culturais e estabelecimentos de ensino privados mais valorizados) dessa região metropolitana (RMSP, doravante) como, por exemplo, os bairros de classe média da 
zona oeste da cidade de São Paulo: maiores polos concentradores de capital cultural na cidade (PEROSA; KERCHES; LEBARON, 2015).

Essa condição de relativa marginalização dentro do universo das classes médias da região metropolitana de São Paulo é academicamente traduzida, aliás, pelo fato de que foi recorrente entre esses informantes os relatos de que eles buscaram acesso à carreira valorizada da engenharia nas instituições universitárias dotadas de maior legitimidade no espaço acadêmico paulista (a USP e a Unicamp). Não tendo sido, entretanto, bem-sucedidos nessa concorrência, esses informantes optaram pelo ingresso na UFABC, não raramente tendo que experienciar ajustes entre suas expectativas subjetivas (de ingresso nessas instituições mais legítimas do campo) e suas condições objetivas, próprias, conforme argumentei, às frações da classe média paulista originadas de lugares geográficos e sociais relativamente marginalizados no contexto da RMSP.

Ainda assim, conforme veremos, as distâncias sociais e culturais, observadas entre os grupos familiares nas duas amostras, são indiscutivelmente extensas e notáveis.

Quanto ao primeiro aspecto destacado por Lareau (2003) - isto é, as disposições linguísticas incorporadas no meio social da família - a maior escolaridade dos entrevistados no cursinho popular ante a média de seus pais (recordemos que $56 \%$ dos pais não possuem o EM completo) torna os informantes do cursinho popular capazes de uma apreensão mais desenvolta, segura e reflexiva da norma culta da língua do que os adultos de seu meio social de origem. Este fato assume expressão bem-humorada e distintiva nas piadas e na caricaturização, frequentemente observada durante a observação etnográfica no cursinho, dos erros e das inadequações recorrentes (sob a métrica da norma culta) que os jovens identificam na fala das pessoas de seu bairro e, até mesmo, de sua família.

A despeito, no entanto, dessa maior segurança e proximidade ante a norma culta, não eram infrequentes os tropeços dos entrevistados nas armadilhas da métrica culturalmente legítima da língua, em nome da qual os jovens costumavam fazer suas blagues em relação a pessoas de seu círculo de relações imediatas, como afirmei acima. Desse modo, seja ao longo das próprias entrevistas de pesquisa, seja ao longo das aulas observadas - ou, ainda, nos textos e redações por eles produzidos ao longo do cursinho - eram frequentes os erros de concordância (a omissão do uso de plurais, sobretudo), de acentuação ou de pontuação.

O mesmo não se observou entre os entrevistados da amostra dos estudantes de engenharia. Ainda que, conforme veremos adiante, esses entrevistados caracterizem-se pela incorporação, desde a socialização familiar, mais de competências lógico-matemáticas do que de competências linguísticas e culturais, os erros de concordância ou a omissão de plurais eram sensivelmente menos frequentes na fala e na transcrição de suas entrevistas. Ademais, eles não relatavam as mesmas dificuldades na composição textual de textos argumentativos ou de redações encontradas entre os estudantes do cursinho popular.

É possível afirmar, portanto, que a maior escolaridade dos jovens do cursinho popular (frente aos seus pais) habilita-os à ironia implicitamente distintiva entre suas formas de 
apropriação da língua e as formas de apropriação correntes entre os adultos de seu meio social. Não obstante, essa maior escolaridade não se evidencia capaz de apagar ou anular, por completo, a incorporação implícita e inconsciente de algo das formas linguísticas correntes no meio social em que esses jovens foram socializados.

Assim, mesmo que sob o efeito de uma escolarização mais elevada, esses jovens incorporam algo das formas linguísticas correntes em seu meio social: formas essas flagrantemente dissonantes ante o domínio da norma culta objetivamente valorado e avaliado nos exames vestibulares. Fato que os coloca, portanto, em condições objetivas de desvantagem ante a concorrência por vagas no ensino superior público perante seus pares de idade de origens sociais mais privilegiadas, como os estudantes de engenharia entrevistados.

Entre esses estudantes de engenharia, é interessante notar, ademais, o considerável grau de hereditariedade profissional encontrado na amostra. Pois, na interpretação e análise do material produzido por meio dessas entrevistas, foram recorrentes os casos de informantes que possuem pais ou tios engenheiros bem como, ainda que de modo menos frequente (dada a conhecida inflexão de gênero desse campo profissional), a presença também relatada de mães engenheiras.

Este fato revela-se como importante à medida que ele é vividamente expresso nos relatos que evidenciam como o convívio familiar entre os estudantes de engenharia e seus pais envolve, desde a infância dos entrevistados, múltiplas interações lúdicas, jogos, brincadeiras, pequenos consertos na casa ou de automóveis da família, nas quais esses pais ou demais familiares com um diploma superior em engenharia transmitiam aos informantes as competências, os interesses, os gostos e as inclinações básicas desse campo profissional especializado: agenciamentos e experiências de socialização de fundamental importância, logo, para a "naturalização" do ensino superior como destino educacional a ser seguido por esses entrevistados a partir de noções fundamentais que orientam, inclusive, a escolha futura de uma carreira valorizada (a engenharia, no caso) nesse nível de ensino (LAREAU, 2003).

Nada semelhante foi narrado pelos entrevistados no cursinho popular investigado. Pois, entre os informantes do cursinho popular e seus pais, o convívio e a fruição do tempo livre (tempo livre ante a escola, para os filhos, e ante o trabalho, para os pais) dá-se a partir de festas de famílias, saídas às ruas ou parques públicos, bem como idas episódicas a shopping centers ${ }^{8}$, sem que os entrevistados discorram sobre o possível incitamento, em tais oportunidades, de curiosidades ou de interesses culturais, tecnológicos ou intelectuais que pudessem servir como base de aproximação desses jovens, primeiro, ante o destino educacional do ensino suSperior e,

8 Enquanto os entrevistados do Allende citam fundamentalmente parques públicos e shoppings como espaço de fruição do tempo livre com seus pais, os entrevistados de classe média mencionam o acesso e frequência a espaços múltiplos. Além dos shoppings e parques públicos, também citados, os entrevistados de classe média mencionam clubes, área de lazer de seus prédios ou condomínios, academias esportivas, cursos extraescolares, viagens, restaurantes, casas de veraneio etc. 
posteriormente, ante a noções ou a experiências que pudessem orientar a inclinação ou o gosto por uma determinada carreira nesse nível de ensino.

Dito de modo mais direto, portanto, na amostra dos estudantes de engenharia, vimos que a socialização familiar aproxima implicitamente os entrevistados do mundo do ensino superior e de suas possíveis carreiras. Através das experiências familiares de fruição do tempo livre, esses jovens foram "familiarizados" e "naturalizados" desde a infância, frente a esse mundo, igualmente frequentado pelos seus pais e familiares.

As mesmas possibilidades de "naturalização" ou de "familiarização" com o mundo do ensino superior e de suas carreiras não foram observadas, entretanto, na amostra dos jovens do cursinho popular, cujas dinâmicas de "familiarização" com o ensino superior ficam na dependência, como vimos, da presença de "modelos impulsionadores" de trajetórias em suas redes de relações imediatas.

Outra diferença referida às formas como a infância e a adolescência são organizadas e vivenciadas por esses dois grupos de entrevistados refere-se ao fato de que os estudantes de engenharia narram uma ampla e múltipla gama de cursos e de atividades extraescolares em que se engajam (ou em que "são engajados" pelos pais) desde crianças. Atividades esportivas, artísticas e destinadas ao domínio de até duas línguas estrangeiras, complementadas por viagens ou intercâmbios (viagens e intercâmbios internacionais, em muitos casos) conformam, ao longo das trajetórias desses jovens, frequentes oportunidades de acumulação de capital cultural para além de seus trajetos de escolarização formal.

Tais oportunidades regulares e variadas para a acumulação de capital cultural se traduzem em vantagens objetivas desfrutadas por esses jovens na concorrência por vagas no ensino superior público. Um exemplo dessas vantagens é, por excelência, o domínio da língua inglesa: competência objetivamente exigida e avaliada pelos exames vestibulares.

É absolutamente significativo, portanto, o fato de que todos os estudantes de engenharia entrevistados declaram o domínio da língua inglesa, antes do ingresso universitário, em virtude de cursos de idioma extraescolares, bem como de experiências de viagens internacionais ou de intercâmbios vivenciados por esses informantes ao longo de suas infâncias ou adolescências (LAREAU, 2003). O mesmo não ocorre entre os estudantes do cursinho popular, entre os quais somente 'autodidatas' na língua inglesa ou raras exceções de estudantes que passaram por cursos de idioma extraescolares ${ }^{9}$ declaram não experienciar maiores dificuldades na avaliação dessa competência em exames vestibulares.

No caso dos estudantes do cursinho popular, portanto, as atividades extraescolares são menos regulares e mais restritas, resultando, no mais das vezes, de oportunidades esparsas ou

\footnotetext{
9 Os casos de "autodidatas" na língua, entre estudantes do cursinho popular, associam-se a jovens que aprenderam o idioma através de uma combinação entre a frequência a cursos extraescolares (geralmente, cursos públicos e gratuitos) e o gosto pela cultura norte-americana através, por exemplo, da tradução de letras musicais de rocks compostos em língua inglesa. Um levantamento junto aos matriculados na iniciativa, durante o ano de 2013, aponta que somente $11 \%$ desses matriculados frequentaram cursos extraescolares de inglês durante mais de dois anos.
} 
temporariamente acessadas a partir de ONGs ou de iniciativas públicas e/ou religiosas sobre as quais os entrevistados tomam conhecimento mediante sua rede de relações com pares de idade na escola ou na vizinhança.

A própria noção de cursos ou de formações extraescolares é espontaneamente interpretada de forma distinta pelos informantes nas duas amostras. Pois, enquanto eu indagava aos estudantes de engenharia quais cursos fora da escola eles haviam frequentado durante suas infâncias e adolescências, eu recebia como resposta essa múltipla gama de atividades e cursos ligados a práticas esportivas (natação, judô, ballet etc.), fazeres artísticos (pintura, música e teatro, sobretudo), bem como os já mencionados cursos de idioma. Já quando eu dirigia a mesma pergunta, expressa em formulação verbal idêntica, aos informantes do cursinho popular, deparei-me, mais de uma vez, com respostas sobre cursos profissionalizantes que os jovens haviam frequentado em paralelo ao ensino médio.

Ao contrário de cursos de idiomas ou de atividades artísticas, frequentemente mencionados e narrados pelos estudantes de engenharia, cursos profissionalizantes raramente podem se inscrever como oportunidades extraescolares para a incorporação de capital cultural, valorado e avaliado - como revela o eloquente exemplo do domínio da língua inglesa - em exames vestibulares. Daí, portanto, torna-se possível concluir que a multiplicidade e a regularidade de frequência a cursos e formações extraescolares configura-se, no comparativo entre as duas amostras, como mais um aspecto da socialização dos jovens do cursinho popular que se revela como dissonante em relação às exigências (implícitas ou explícitas) dos exames vestibulares de instituições públicas.

\section{Conclusão: um movimento dialético}

Ao longo do texto, vimos, primeiramente, três agenciamentos de socialização familiar que incitam a incorporação de disposições que afastam a perspectiva de "autoeliminação escolar" entre os informantes do estudo: A) a distinção moral e disciplinar que ampara propensões ao investimento escolar por parte dos informantes; B) agenciamentos parentais (sobretudo, maternos) operados no sentido de evitar a ocorrência de casos de gravidez "precoce" que poderiam obstaculizar as trajetórias educacionais dos informantes; e C) a presença de "modelos impulsionadores" de trajetórias educacionais nas redes de relações dos informantes. No que tange à incorporação dessas disposições entre os informantes, vale afirmar que os agenciamentos responsáveis pela "moratória temporária" ante a entrada no mundo do trabalho, concedida aos entrevistados pelos seus pais, também se inscreve como uma dimensão da socialização familiar relevante para o afastamento da perspectiva de "autoeliminação escolar". Não foi possível tratar dessa dimensão, nos limites do texto, embora ela seja plenamente tematizada no estudo mais amplo cujos principais resultados este artigo buscou sintetizar (BONALDI, 2016).

Quanto às dissonâncias e desajustes experienciados por esses jovens em suas tentativas 
de acesso ao ensino suSperior público, vale igualmente notar que as dimensões da socialização familiar aqui abordadas conectam-se aos trajetos de escolarização precários ou deficitários a que muitos dos informantes foram expostos nos estabelecimentos de ensino pelos quais eles passaram (BONALDI, 2016): conexão esta que evidencia integralmente, portanto, a ampla extensão das dissonâncias e das barreiras que esses jovens encontram ao passarem da tendência à "autoeliminação escolar" ao enfrentamento incerto da concorrência por uma vaga no ensino superior brasileiro, sobretudo em seu setor público,: destino aspirado por esses jovens a partir de suas passagens pela iniciativa abordada no estudo.

Desse modo, tanto o artigo, quanto o trabalho em que ele se apoia (BONALDI, 2016), buscam evidenciar o movimento caracteristicamente dialético, transcorrido ao longo da socialização e da escolarização dos informantes do estudo, segundo o qual a incorporação das disposições que os incitam à superação da "autoeliminação escolar" desdobra-se, para além da vontade consciente desses agentes, em desajustes, limites e inadequações experienciados, por tais agentes, em suas tentativas de acesso ao ensino suSperior público nacional. Nesse sentido, o presente texto buscou ofertar ao leitor, portanto, a descrição e a interpretação qualitativa desse movimento dialético próprio às experiências e trajetórias de jovens, originados de camadas populares e urbanas, que buscam se inserir no recente contexto de expansão do ensino superior nacional a partir da iniciativa de cursinho popular abordada no estudo.

\section{Referências}

ALMEIDA, Ana Maria F. As escolas dos dirigentes paulistas: ensino médio, vestibular, desigualdade social. Belo Horizonte: Argumentum, 2009. .

ALMEIDA, Ana Maria F.; ERNICA, Maurício. Inclusão e segmentação social no Ensino superior público no Estado de São Paulo (1990-2012), Educação e sociedade, Campinas, v. 36, n. 130, p. 63-83, 2015.

BAUDELOT, Christian; ESTABLET, Roger. L'école primaire divise Paris: Maspéro, 1975.

BEAUD, Stéphane. 80\% au BAC... et après? Paris: Éditions La Découverte, 2002.

BONALDI, E. V.; SILVA, E. B. Gendered Habitus in Engineering: Experiences of Brazilian Students. International Journal of Gender, Science and Technology, v. 6, n.1 p. 144, mar. 2014.

BONALDI, E. V. Tentanto chegar lá: As experiências sociais de jovens em um cursinho popular em São Paulo. 2016. 404 f. Tese (Doutorado em Sociologia) - Programa de Pós-graduação em Sociologia, Universidade de São Paulo, São Paulo.

BOUDON, Raymond. L'inégalité des chances: la mobilité sociale dans les sociétés industrielles. Révue Française des Sciences Politique, Paris, . 24, n.6, pp 1268-1273, 1974.

BOURDIEU, Pierre. Classificação, desclassificação e reclassificação In: NOGUEIRA, Maria Alice; CATANI, Afrânio. (Orgs.). Escritos de Educação. Petrópolis: Vozes, 1998. p. 145-184.

. Excluídos do interior. In: NOGUEIRA, Maria Alice; CATANI, Afrânio (Orgs.). Escritos de Educação Petrópolis: Vozes, 1998. p. 217-228.

; PASSERON, Jean-Claude. Les Héritiers: les étudiants et la culture. Paris: Les Éditions de Minuit, 1964. 
La Reproduction. Paris: Les Éditions de Minuit, 1970.

BOWLES, Samuel; GINTIS, Herbert. Schooling in capitalist America: Educational Reform and contradictions of economic life. New York: Basic Books, 1976.

BRASIL. Ministério da educação. Resumo técnico do censo da educação superior de 2011. Brasília: Instituto Nacional de Estudos e Pesquisas Educacionais Anísio Teixeira - INEP, 2013. Disponível em:http://portal.inep.gov.br/ web/censo-da-educacao-superior. Acesso em: 07 out. 2013.

DURKHEIM, Émile. Educação e sociologia São Paulo: Melhoramentos, 1975.

GRÜN, Roberto. Negócios \& famílias: Armênios em São Paulo. São Paulo: Idesp, 1992.

LAHIRE, Bernard. Sucesso escolar nos meios populares: razões do improvável. São Paulo: Editora Ática, 1997.

LAREAU, Annette. Unequal Childhoods: class, race and family Life Berkeley: University of California Press, 2003. LIMA, Márcia. As novas políticas de inclusão escolar e as famílias: o caso dos beneficiários do Prouni na Região Metropolitana de São Paulo. In: ROMANELLI, Geraldo; NOGUEIRA, Maria Alice; ZAGO, Nadir. (Orgs.). Família e escola: novas perspectivas de análise. São Paulo: Vozes, 2013. p. 312-333.

MESQUITA, Wilson A. Ampliação do acesso ao ensino superior privado lucrativo brasileiro: um estudo sociológico com bolsistas do Prouni na cidade de São Paulo. 2012. 294 f. Tese (Doutorado em Sociologia) - Faculdade de Filosofia Letras e Ciências Humanas, Universidade de São Paulo, São Paulo.

NOGUEIRA, Maria Alice. Estratégias de escolarização em famílias de empresários. In: ALMEIDA, Ana; NOGUEIRA, Maria Alice. (Orgs.). A escolarização das elites: um panorama internacional da pesquisa. Petrópolis: Vozes, 2002. p. 49-65.

PARSONS, Talcott. The school class as a social system: Some of its functions in American societies In: Social Structure and Personality. New York: Free Press, 1964. pp. 129-154.

PEROSA, Graziela Serroni; COSTA, Taline de Lima E. Uma democratização relativa? Um estudo sobre o caso da expansão da Unifesp. Educação e sociedade, Campinas, v. 36, n. 130, p. 117-137, 2015.

PEROSA, Graziela S., KERCHES, Cristiane, LEBARON Frédéric. O espao das desigualdades educativas em São Paulo Pro-posições, São Paulo, v. 27, n.2, p. 99-118, 2015.

ROMANELLI, Geraldo. Famílias de camadas médias e escolarização superior dos filhos: o estudante-trabalhador In: NOGUEIRA, Maria Alice; ROMANELLI, Geraldi; ZAGO, Nadir. (Orgs.). Família \& escola: trajetórias de escolarização em camadas médias e populares. 2 ed. Petrópolis: Vozes, 2003. p. 199-225.

ROMANELLI, Geraldo; NOGUEIRA, Maria Alice; ZAGO, Nadir. (Orgs.). Família e Escola: trajetórias de escolarização em camadas médias e populares. Petrópolis: Editora Vozes, 2003.

SILVA, Jaílson. Por que uns e não outros? Caminhada de jovens pobres para a universidade. Rio de Janeiro: Sete Letras, 2003.

TERRAIL, Jean-Pierre. Parents, filles et garçons, face à l'enjeu scolaire. Éducation et Formations, Paris, n. 30, p. 3-11, 1992.

VIANA, Maria J. B. Longevidade escolar em famílias de camadas populares: algumas condições de possibilidades. 1998. 414 f. Tese (Doutorado em Educação) - Faculdade de Educação, Universidade Federal de Minas Gerais, Belo Horizonte.

ZAGO, Nadir. Do acesso à permanência no ensino superior: percursos de estudantes universitários de camadas populares. Revista Brasileira de Educação, Rio de Janeiro, v. 11, n. 32, p. 226-237, 2006. 
_. Cursos pré-vestibulares populares: limites e perspectivas. Perspectiva, Florianópolis, v. 26, n. 1, p. 149-174, 2008.

WILLIS, Paul. Aprendendo a ser trabalhador: escola, resistência e reprodução social. Artes Médicas: Porto Alegre, 1991.

Recebido em: 02/06/2017

Aceito em: 27/08/2018 